\title{
Sosa on Reflective Knowledge and Knowing Full Well
}

Jack Lyons

University of Arkansas

Sosa's newest book, Knowing Full Well , is an impressive contribution to the field. It displays a remarkable breadth of focus, weighing in on a wide range of issues in contemporary epistemology, from the value problem and the bootstrapping problem, to contextualism and knowledge as the norm of assertion. The unifying theme in all this is Sosa's virtue theoretical idea of knowledge as successful performance: epistemic normativity, on his view, is a species of performance normativity; performances more generally are evaluable with respect to whether they succeed in their aims by manifesting a competence, and epistemic evaluation is just a special case where the performance is belief with the aim of truth. In typical Sosa fashion, the contemporary problems are not treated as isolated puzzles, but are connected with and brought to bear on the central traditional concerns of epistemology, tracing back through Moore and Descartes.

There are too many themes here for me to discuss more than a few in any detail, so I want to focus on the titular topic of knowing full well and the related topics of animal and reflective knowledge. Animal and reflective knowledge have obviously played an important role---and perhaps different roles---in Sosa's epistemology over the years, and I won't try to trace in any detail the evolution of his views on this distinction; I focus mainly on where it stands now.

Let me start with a simplified overview. Animal knowledge is first-level unreflective knowledge, which is a matter of getting things right through the exercise or manifestation of a skill or competence. In the triple-A terminology Sosa uses, a belief can be "accurate" (true), "adroit" (competently/reliably produced), and, most importantly, "apt" (accurate because adroit). Animal knowledge is thus apt belief. Reflective knowledge is, roughly (more on this shortly), apt belief aptly noted; not only is the agent getting things right at the object level as the result of a cognitive competence, but the agent is manifesting

I Sosa (2OII). Henceforth, "KFW"; all otherwise specified page number citations will refer to this work. 
a meta-level competence for distinguishing her object-level competences from incompetences. Importantly, such meta-level competences need not be restricted to post hoc upgrading of animal knowledge to reflective knowledge; they can serve to influence and guide the formation of object-level beliefs. This opens up the possibility of object-level belief that is apt because meta-apt: the object-level competence is itself a manifestation of a meta-level competence. Here, finally, we have knowing full well: belief that achieves success (truth) as the result of a cognitive competence, where this object-level competence is itself the result of a higher-order reflective competence.

The animal/reflective distinction is susceptible to an internalist-friendly as well as an externalist reading. In fact, it is easy to see the animal/reflective knowledge distinction as making such a large concession to internalism that the result is actually a defense of internalism. An internalist should be happy with the claim that there is some sense of 'knowledge' according to which apt belief counts as knowledge. In this sense, unsophisticated children and animals---and even thermometers---have knowledge, if we insist on calling it that, though of course what they have is mere animal knowledge. Reflective knowledge and knowing full well are better, higher grades of knowledge than mere animal knowledge. This claim could easily be read as marginalizing animal knowledge to such an extent that the finished view is one that even a staunch internalist like BonJour might be willing to accept. ${ }^{2}$

An externalist without any internalist sympathies or misgivings, on the other hand, might hold that animal knowledge is really the main event, that the higher grades of knowledge are---to switch metaphors---mere icing on the cake. An externalist might thus hold that knowledge is basically a matter of apt belief and that some people, sometimes, in the course of certain intellectual pursuits, aspire to and sometimes achieve something even greater, but that it is a mistake for the internalist to confound this fancy and relatively rare epistemic status with regular old knowledge, the stuff that epistemology has been traditionally concerned with, the stuff that the skeptical arguments conclude we don't have any of. So long as skeptical scenarios don't in fact obtain, we can have knowledge of the external world without our having to in any sense rule out those scenarios.

${ }^{2}$ See BonJour and Sosa (2003). 
Sosa's position seems to be somewhere in the middle of these. On the one hand, his view is clearly externalist; the internalist is not even right about reflective knowledge. Reflective knowledge is a matter of having a meta-level competence, but competence is still an externalist notion, whether directed outward at the world or inward at our own objectlevel competences.

Also, in KFW's treatment of instrumental knowledge, Sosa claims that the senses are different from the instruments that don't make up part of our native animal endowment, in that the latter, but not the former, require some kind of metajustification to produce any knowledge or justification (pp. 137-9). Thus, I can get animal knowledge from the unreflective use of my eyes but not from the unreflective use of my crystal ball, or even of my (reliable) speedometer. 3 Sosa must think that animal knowledge really is knowledge in some robust sense; otherwise, why distinguish between an unreflective reliance on perception and an unreflective reliance on external instruments?

On the other hand, however, KFW differs from earlier work in subtle ways that suggest movement away from the more severe externalism. For example, where an earlier discussion talked about "animal justification" and "reflective justification" (Sosa 2009, pp. 238-9), KWF contrasts "reflective justification" with "animal competence" (pp. 149-50). The two discussions otherwise parallel each other closely enough that the replacement of 'justification' with 'competence' seems to have been a deliberate choice.

So how internalist-friendly is Sosa's current view? To answer this, we will need a better understanding of what reflective knowledge is. What level of cognitive sophistication is required for it? Is it really a higher grade of knowledge than animal knowledge, and what exactly does that mean?4

\footnotetext{
3 Sosa is thus endorsing a distinction between epistemic sources that can provide epistemically basic beliefs and those whose deliverances require reflective endorsement in order to have any positive epistemic standing. I'm glad to see this, as this has been a major concern of my own (Lyons 2009), although I have focused more on inferential basicality than on hierarchical basicality (see Sosa $2009, \mathrm{p} x x x$ for the distinction). I think there may also be strong similarities between Sosa's and my views about which beliefs are basic and why. Although I hadn't thought to apply the basic/nonbasic distinction to the bootstrapping problem, James Simmons (cite) has.

4 I'll assume that animal and reflective knowledge have corresponding senses of justification and that the relations between the respective knowledges and justifications are straightforward, with the caveat noted in the previous paragraph.
} 
Sosa appears to offer three different accounts of what reflective knowledge is, in KFW:

(I) apt metabelief: i.e., apt belief, aptly noted: this is simply an additional animal competence whose target happens to be the aptness of a first-order belief, rather than ordinary facts about the external world. One has reflective justification in this sense just in case one competently believes that some other belief was competently arrived at. 5

(2) meta-aptness: this is a matter of "selection competence," of knowing when to act (e.g., shoot an arrow, adopt a belief, etc.) and when to forbear or withhold. ${ }^{6}$

(3) coherence: having a comprehensive reflective perspective, one that presumably includes not (just) reliably produced metabeliefs, but explanatory power, simplicity, comprehensiveness, etc. 7

These are not the same and in fact might have little to do with each other.

Presumably an organism complex enough to count as having beliefs could nevertheless have a host of pretty simplistic perceptual competences, regarding which that organism is little more than a thermometer. But if it could reliably detect external properties in this thermometer-like way, it could be wired up to do the same concerning the reliability of some of these same mechanisms. Here, then, is reflective knowledge in a creature whose cognition is limited to thermometer-like detection capacities. It needs enough conceptual sophistication to entertain beliefs about beliefs and reliability and the like, but the means by which it comes to these beliefs, and the evidence (if any) from which it draws them, need not be at all complicated or sophisticated. One might thereby know that one knows without having any idea how or why one knows. I doubt that this form of reflective knowledge would by any kind of olive branch to the internalist.

\footnotetext{
5 This is more prominent in some earlier work, especially Sosa (2007), but it makes an appearance here as well: "Reflective knowledge is animal belief aptly endorsed by the subject (p. II)." "Apt belief aptly noted, reflective knowledge, is better than mere apt belief or animal knowledge (pp. I2-I3)." Cf. p. 92, 150.

${ }^{6}$ This is the one that is emphasized most strongly in KFW, especially Chapter I.

7 "Proper reflective knowledge will after all satisfy requirements of coherence, which means not just logical or probabilistic coherence of the respective belief contents, but also the mutual basing relations that con properly reflect such coherence among the contents. Cross-level coherence, from the object to the meta, and conversely, is a special case of such coherence (p. 13, note 6)." The use of 'proper' here might suggest that Sosa is reserving coherence for a special species of reflective knowledge, but the appeal to coherence in Chapter 8 of KFW suggests otherwise.
} 
Sosa introduces the notion through the example of an archer who is also a hunter and thus must not only be good at hitting targets but also at selecting targets, at knowing when to shoot and when to forbear. In this sense, meta-aptness is fairly common; cats and other predatory animals exhibit meta-aptness. A cat stalking a mouse frequently exhibits restraint until the prey is in proper range; cats forbear. ${ }^{8}$ I doubt that cats do so by forming implicit or explicit beliefs about object-level competences; what beliefs they have are probably about the prey being too far, or poorly positioned, or whatever. If this is right, then cats enjoy meta-aptness without having apt metabeliefs. Having apt metabeliefs is one way to achieve meta-aptness, but it's not the only way. Conversely, meta-aptness is a performative skill and as such, I would think, requires a certain amount of self-restraint. One could be quite accurate in one's meta-level self assessments without having any self-restraint and thus, it would seem, without having meta-aptness. So meta-aptness neither implies nor is implied by apt metabelief.

Similarly, coherence is neither necessary nor sufficient for either apt metabelief or for meta-aptness. Cats and thermometers don't (or needn't) have coherent reflective perspectives, so coherence isn't necessary. Coherence doesn't suffice for self-restraint, so it doesn't suffice for meta-aptness. And since coherence doesn't imply reliability, it doesn't suffice for apt metabelief either. 9

Thus, aptness of metabelief, meta-aptness, and coherence are three distinct properties. They all strike me as epistemically desirable, and I'm happy to allow that there are three varieties of reflective knowledge. It might even be that the epistemically best state is when all three come together in the aptness-producing guidance of object-level belief, when the development of a coherent perspective gives us evidence for the reliability of some of our first-order competences, and this in turn gives us practical knowledge of when to believe and when to forbear, all of which then increases our object-level reliability.

When Sosa claims that reflective knowledge is a different kind of knowledge than animal knowledge, he seems to mean it in much the way that Descartes does when he says

\footnotetext{
${ }^{8}$ This is armchair ethology here, based only on casual observations of a small (but random) selection of household pets.

9 I think that coherence doesn't even imply the presence of a metabelief: "Cross-level coherence, from the object to the meta, and conversely, is a special case of such coherence [viz., the kind of coherence involved in reflective knowledge] (p. I3, note 6, italics added).”
} 
that scientia is a different kind of knowledge than cognitio. They are not just different types of knowledge, in the sense that perceptual, testimonial, memory, inductive, abductive knowledge, etc. are different types; they are different grades of knowledge: reflective knowledge is a superior type of knowledge than animal knowledge. But it's hard to see what this claim might amount to or how one would defend it. A standard kind of externalism can happily admit that reflective knowledge in the sense of, say, apt metabelief can increase one's degree of justification. But this is little different from the claim that your knowledge derived from seeing that $p$ is boosted by your friend's testifying that she sees it too.

I hear a familiar sort of barking noise next door and form the perceptual belief that there's a dog in my neighbor's yard. Next, I remember that she had a dog as of last week, perform a bit of induction, and now my justification has increased by a small amount (how small depends on details, including how clear the auditory percept was, etc.). Why should reflection in any of the three senses examined above be any different? My own view is that it is not; forming an apt metabelief or the like adds to the justification of an ordinary perceptual belief, but only in a corroborative sense. Some forms of reflection (viz., I and 3) transform a belief from being a noninferential perceptual belief to being a partly perceptual/ partly inferential belief, but it is unclear why this kind of corroboration transforms a piece of knowledge into a "better" grade of knowledge, in a way that other forms of corroboration do not.

One answer may be that reflective knowledge, unlike animal knowledge that is corroborated by nonreflective means, offers an answer to certain skeptical worries. Skeptical arguments often feature the requirement that we know our first-order capacities to be reliable. Reflective knowledge would answer that demand. Perhaps, but there are two problems with this move. First, if this works, it only works for the apt metabelief sense of reflective knowledge; in particular, it doesn't seem to work for the meta-aptness sense of reflective knowledge that is the focus of KFW.

Second, it seems that the proper response to skepticism is to reject that demand, not to satisfy it. Sosa claims that we can have perceptual knowledge without reflection, and this is not simply a matter of our getting things right, and doing so safely (i.e., it not being the case that we might easily have gotten things wrong). We can get that from blind trust in a reliable instrument. The point is this: there is a highly deflationary and revisionary sense of 
'know' according to which even the internalist would grant that blind reliance on instruments yields a kind of "knowledge." The skeptic never denied that we have that kind of "knowledge." But the fact that Sosa distinguishes between the unreflective reliance on perception and the unreflective reliance on external instruments shows that he doesn't have that sense of 'knowledge' in mind; instead he is using the term in a robust and ordinary way. So the skeptic is simply wrong to claim that we can't get knowledge from our first-order capacities unless we know these capacities to be reliable. Showing how we can have such meta-level knowledge is a nice bonus, but it's no longer central to one's response to skepticism. Sosa's satisfying the skeptic's demand here depends on his rejection of that demand. We can have knowledge of the reliability of our capacities, but only in the externalist sense of knowledge. ${ }^{\circ}$

But if reflective knowledge doesn't add anything to the externalist response to skepticism, then that can't explain why we should view it as a better grade of knowledge. In fact, it seems that animal knowledge is frequently or typically epistemically superior to reflective knowledge. It is rare for us to have reflective knowledge or justification without animal knowledge or justification, but consider an unusual case. Patients with prosopagnosia have an inability to visually recognize faces, though they are typically able to visually recognize facial features; they can see that the person in front of them has brown curly hair, a hooked nose, a dimpled chin, etc. Prosopagnosics are thus cut off from the normal animal justification that accompanies our face identification judgments (e.g., "that's Martha in front of me"), but they can still work out reflective arguments for face identification judgments. They're terrible at it, not surprisingly, so they probably couldn't achieve knowledge this way, but there's no obvious obstacle to meta-level justification here. Still, it seems clear that the degree of justification they get from such reflective ascent is far inferior to the degree of justification from the ordinary, animal belief. Epistemically speaking, I would rather just see that there's a pen in front of me than reason it out through reflection on my own first-order competences. Sure, it's better to see it and have reflective corroboration than merely to see it, just as it's better to see it and have testimonial corroboration that your friend sees it too.

\footnotetext{
Io Even on the coherence understanding of reflective knowledge, it is a contingent, and hence external, matter whether coherence produces a competence. Sosa (2009) claims that coherence doesn't lead to truth in demon worlds, but because it does in the actual world, coherence still constitutes a competence. From an internalist's perspective, this is a lot like saying that perception yields knowledge because it is actually reliable.
} 
But this doesn't show that reflective justification by itself is in any interesting sense superior to animal justification.

I don't know that this conflicts with anything Sosa is committed to, but it is a point worth emphasizing regardless. Many philosophers used to think that a priori justification was intrinsically superior to a posteriori justification, in the sense that a person with an a priori justification for $p$ is thereby automatically in a better epistemic position than the person with the merely a posteriori justification for $p$. This is plainly false; I have much better justification for thinking I'm wearing shoes than for thinking that the A-theory of time is correct. Similarly, some philosophers have held that reflective justification is intrinsically superior to animal justification. I think this is plainly false as well. ${ }^{\mathrm{II}}$

In saying all this, I fully concede and insist that reflective knowledge is an important and interesting variety of knowledge, that it is a distinctively human sort of knowledge, and that we rightly cherish it in a way that we don't value mere animal knowledge, although I suspect that we value it for nonepistemic reasons. Reflective knowledge is knowledge of something that is of great interest to us, especially to the epistemologists among us.

The type of reflective knowledge that is the most distinctive, valuable, and interesting is the apt metabelief type, perhaps especially in the context of a coherent overall perspective. But the type that seems to occupy center stage in KFW is meta-aptness, or selection competence. For this reason, it is worth saying a bit more about meta-aptness and how it is related to both object-level aptness and the other types of reflective knowledge, particularly apt metabelief.

Let's call an epistemic competence "reflective" only if it involves beliefs, judgments, or commitments concerning beliefs, experiences, or other mental states. Much of the work that reflective knowledge is supposed to do in KFW, especially the last two chapters on bootstrapping, skepticism, and epistemic circularity, seems to require reflective knowledge to really be reflective in this sense. But meta-aptness is not reflective in this sense. Because knowing full well is defined in terms of meta-aptness, one could know full well without any

\footnotetext{
II I'm not claiming that it's plainly false that reflective justification is necessary for object-level justification, i.e., ordinary justification about external objects. I think it's false, but not plainly so. We are considering here the view that animal justification/knowledge exists independently of reflective justification/knowledge. If so, then the latter clearly isn't superior to the former.
} 
understanding of how or why she knows. I don't think Sosa wants this result. I see two plausible lines of response. The first is to argue that meta-aptness, in the sense of knowing when to act and when to forbear, really does require reflection; the other is to simply redefine meta-aptness as reflective selection competence.

The first seems unattractive for reasons mentioned earlier. One can have a selection competence without having the conceptual resources for reflection. Animals and small children certainly seem to exhibit selection competence in nonepistemic realms. And even in the epistemic sphere, such selection competences might be built into certain cognitive modules, such that they simply don't deliver outputs when conditions are bad. Vision sometimes represents some regions as empty, but it doesn't usually do so in the dark; in the dark vision remains silent, agnostic, forbearing.

The second option is much more appealing, though not entirely unproblematic. Selection competence is introduced in Chapter I to solve the problem of withholding, to provide an account of how not only beliefs but also suspensions of belief can be epistemically justified. In a way, this understates the importance of the problem, for the difficult question is how a withholding can be unjustified. Withholding is justified (i.e., better than believing) whenever believing would have not manifested a competence. An epistemology that recognizes only belief-forming virtues accounts for this well enough. Something further is needed to claim that some withholdings are epistemically inappropriate. And some certainly are; some people appear to withhold belief about evolution, global warming, or the President's US citizenship. Such withholding---if genuine---is epistemically unjustified.

One account for this would appeal to parity of evidence: you can set your evidential threshold for belief wherever you like, within limits, so long as you do so uniformly. Some of the people who are agnostic about evolution nevertheless believe that Jonah really spent three days in the belly of a whale, even though there's far more evidence for the former than for the latter. The problem is not having high evidential standards; the problem is having selectively high epistemic standards, i.e., high for some propositions but not others. I think this parity principle is correct, but it doesn't go far enough. We can cover a broader range of withholdings (since not all beliefs or withholdings are evidential, or reasons-involving) by recognizing epistemic virtues and vices pertaining to withholding as well as belief. This 
approach should subsume the evidential approach, since violating the parity principle is an exercise of an epistemic vice.

Thus, Sosa's treatment of selection competence is a valuable addition to his theory. But selection competence can do the important work just described entirely at the animal level. There is no need for genuine reflection here. Sosa could amend the Chapter I discussion of selection competence by specifically requiring reflective selection competence, but that would be overkill, since nonreflective selection competence solves the problem of withholding just as well. The upshot, then, is that Sosa has a genuinely reflective conception of reflective knowledge (or maybe two such conceptions), and an additional conception of selection competence that is neutral regarding reflectivity: some selection competencies are animal, some reflective. Each has an important role to play in his overall theory (though I have argued that genuine reflection plays less of a role than it might appear to play), but it is not one thing doing both jobs.

\section{References:}

BonJour, L., and E. Sosa (2003). Epistemic Fustification: Internalism vs. Externalism, Foundations vs. Virtues. Blackwell.

Lyons, J. (2009). Perception and Basic Beliefs. New York: Oxford University Press.

Sosa, E. (2007). A Virtue Epistemology: Apt Belief and Reflective Knowledge, Volume I. Oxford: Oxford University Press.

Sosa, E. (2009). Reflective Knowledge: Apt Belief and Reflective Knowledge, Volume II. Oxford:

Oxford University Press.

Sosa, E. (201I). Knowing Full Well. Princeton, NJ: Princeton University Press. 